\title{
Analysis of a new genetic cross between two East African Trypanosoma brucei clones
}

\author{
J. SCHWEIZER ${ }^{1}$, H. POSPICHAL ${ }^{1 *}$, G. HIDE ${ }^{2}$, N. BUCHANAN ${ }^{2}$, A. TAIT ${ }^{2}$ and L. JENNI \\ ${ }^{1}$ Swiss Tropical Institute, Postfach, CH-4002 Basel, Switzerland \\ ${ }^{2}$ Wellcome Unit of Molecular Parasitology, University of Glasgow, Bearsden Road, Glasgow G61 1QH, Scotland
}

(Received 15 July 1993 ; revised 8 November 1993 ; accepted 11 November 1993)

\begin{abstract}
SUMMARY
Two clones of East African Trypanosoma brucei, with distinct homozygous isoenzyme patterns for one of three enzymes examined, were cotransmitted through the tsetse fly vector Glossina morsitans centralis. Flies with mature infections were individually fed on mice and the subsequent bloodstream form populations analysed for the presence of hybrid trypanosomes by isoenzyme analysis. Several combinations have previously been detected using this approach (Schweizer, Tait \& Jenni, 1988; Sternberg et al. 1989). Four clones were isolated from one of the hybrid-containing populations. They showed a hybrid phenotype, as would be expected for the F1 progeny in a diploid Mendelian system. The analysis of the progeny clones, using two gene probes which detect restriction fragment length polymorphisms between the two parental stocks, showed that alleles had segregated at each locus and given rise to three different non-parental combinations of alleles in the hybrid progeny. Characterization of the hybrid progeny clones by PFGE (pulsed field gradient gel electrophoresis) revealed that all progeny clones were recombinant for the intermediate size chromosomes. From the analysis of the segregation of the larger chromosomes, marked by PGK (phosphoglycerate kinase) and CP (cysteine protease) gene probes, it was inferred that the progeny clones did not result from a direct fusion of diploid cells. Results with the PGK probe fit into a classical system with meiosis and subsequent fusion of the nuclei to form diploid progeny. On the other hand, blots with the CP probe as well as some of the ethidium bromide stained PFGE gels revealed the existence of non-parental size chromosomes in some of the hybrid progeny. This phenomenon was observed previously (Gibson, 1989) and further investigation is required to elucidate the mechanism.
\end{abstract}

Key words: Trypanosoma (T.) brucei, genetic exchange, isoenzyme analysis, restriction fragment length polymorphism, karyotype analysis.

\section{INTRODUCTION}

Until recently, Trypanosoma brucei, the causative agent of African sleeping sickness in man and nagana disease in cattle, was believed to multiply solely by binary fission. In the early 1980s the first evidence for the existence of a mating system was obtained indirectly from the electrophoretic analysis of enzyme variation between stocks isolated from natural populations (Gibson, Marshall \& Godfrey, 1980; Tait, 1980; Tait et al. 1985). Later, direct demonstration of genetic exchange after the cotransmission of two phenotypically different $T$. brucei clones through the tsetse fly vector was provided by Jenni et al. (1986). These results gave rise to a wide range of new questions and, as a consequence, investigations have concentrated mainly on three topics: (1) frequency of gene exchange (Schweizer et al. 1988; Sternberg et al. 1989), (2) the localization of the stage in the parasite's life-cycle when genetic exchange occurs (Schweizer \& Jenni, 1991; Gibson \& Whittington, 1993), and (3) the mechanisms

* Reprint requests to: Harry Pospichal, Swiss Tropical Institute, Postfach, CH-4002 Basel, Switzerland. involved in hybrid formation. In order to understand trypanosome mating, the analysis of numerous hybrid progeny clones from different parental combinations and independent crosses is indispensable. Up to now 8 different crosses have been described (Jenni et al. 1986; Paindavoine et al. 1986; Wells et al. 1987; Sternberg et al. 1988, 1989; Gibson, 1989; Gibson \& Garside, 1990; Turner et al. 1990; Gibson \& Whittington, 1993). In this paper we provide additional data on gene exchange by the characterization of four hybrid clones from a further cross between two East African Trypanosoma brucei parental clones.

\section{MATERIALS AND METHODS}

\section{Trypanosomes}

Two East African T. brucei clones - both showing distinct homozygous isoenzyme patterns for isocitrate dehydrogenase (ICD; EC 1.1.1.42)-were chosen for simultaneous transmission through the tsetse fly vector.

$S T I B$ (Swiss Tropical Institute Basel) $247-L F$ is a restabilate of clone $S T I B 247-L$ after passage 
Table 1. Isolated and characterized (isoenzyme analysis for ICD) bloodstream-form populations from mixed infected Glossina morsitans centralis at different days after fly infection

(P1, P2, homozygous ICD (isocitrate dehydrogenase) patterns characteristic for bloodstream forms of parental clones $\mathrm{P} 1$ (STIB 247-LF) and $\mathrm{P} 2$ (STIB 777-A), respectively. Hy, heterozygous hybrid pattern. $\mathrm{P} 1 / \mathrm{P} 2$, simultaneous homozygous patterns of both parental clones.)

\begin{tabular}{lllllll}
\hline \hline & \multicolumn{6}{l}{ Time post-infection (days) } \\
\cline { 2 - 7 } Fly & 24 & 31 & 38 & 40 & 45 & 55 \\
\hline AI & & & & & P1/P2 & \\
AU & & & & & P1 & P1 \\
AW & P1 & & P1 & & P1 & P1 \\
BF & P1/P2 & P2 & P1/P2 & Hy & \\
BJ & & P1 & & P1 & & \\
BX & & & Hy & & Hy & \\
CN & & & P1 & & P1 & \\
\hline \hline
\end{tabular}

through Glossina; this stock originates from a population from a Coke's hartebeest in the Serengeti National Park, Tanzania (Geigy \& Kaufmann, 1973) and was used for earlier mixed-infection experiments (Jenni et al. 1986; Sternberg et al. 1989). Clone $S T I B 777-A$ is derived from the population $K E T R I$ (Kenyan Trypanosome Research Institute) 1957 (Gibson \& Gushumba, 1983), isolated in 1971 from a wild-caught Glossina fuscipes in eastern Uganda.

\section{Tsetse flies and cyclical transmission}

Teneral Glossina morsitans centralis were membrane fed on an equal mixture $\left(3 \times 10^{7}\right.$ trypanosomes $\left./ \mathrm{ml}\right)$ of bloodstream forms of both parental clones $S T I B$ 247-LF (P1) and STIB 777-A (P2); fly handling and maintenance were performed as described by Schweizer et al. (1988). Infective flies - identified by probing on warmed slides - were repeatedly fed on Swiss ICR mice and the subsequent bloodstreamform trypsanosomes were cryopreserved. A total of 17 stabilates from 7 different flies were thus obtained and after expansion in mice and purification of the trypanosomes were subsequently screened for hybrids by isoenzyme analysis for ICD.

\section{Cloning}

Cloning was performed on progeny population $S T I B 787-I$, isolated from fly $\mathrm{BX}$ on day 38 after infection which was chosen at random from the three populations which had been shown to contain hybrid trypanosomes (Table 1). The bloodstream form trypsanosomes were therefore thawed and used to infect a lethally $\mathrm{X}$-irradiated $(650 \mathrm{rad}$; radiation absorbed dose) Swiss ICR mouse. After a sufficient level of parasitaemia had been reached, single trypanosomes from tail blood were cloned intraperitoneally into a total of 19 ICR mice using the hanging drop method (Van Meirvenne, Janssens \& Magnus, 1975). Four clones were isolated (designated as $S T I B$ 787-IA, 787-IB, 787-IC and 787-ID respectively), cryopreserved and subsequently characterized by isoenzyme and molecular karyotype analysis.

\section{Isoenzyme analysis}

The preparation of bloodstream-form lysates was performed as described by Schweizer et al. (1988). Starch gel electrophoresis, electrophoresis buffers and the stains used for ICD and AP (alkaline phosphatase; EC 3.1.3.1) have previously been described (Tait, Babiker \& Le Ray, 1984). Isoelectric focusing for $\mathrm{ME}_{\mathrm{B}}$ (malic enzyme $\mathrm{B}$; EC 1.1.1.40) was carried out according to Richner et al. (1989) except for pre-focusing, which was carried out at $220 \mathrm{Vh}$.

\section{Restriction fragment length polymorphism analysis}

Isolation of trypanosome DNA (deoxyribonucleic acid) as well as DNA-electrophoresis, Southern hybridization and restriction fragment length polymorphism (RFLP) analysis was carried out as previously described (Gibson et al. 1985; Jenni et al. 1986; Wells et al. 1987; Sternberg et al. 1989) using probes for phosphoglycerate kinase (Osinga et al. 1985) and RNA-polymerase I (Jess, Hammer \& Cornelissen, 1989).

\section{Pulsed field gradient gel electrophoresis}

Molecular karyotype analysis by pulsed field gradient gel electrophoresis, PFGE (Schwartz \& Cantor, 1984) was performed on procyclic forms. Bloodstream-form trypanosomes of the different clones were transformed in vitro according to a slightly modified (Schweizer, Pospichal \& Jenni, 1991) method of Brun \& Schönenberger (1981).

The trypanosomes were prepared in blocks in lowgelling temperature agarose at $2.5 \times 10^{8} / \mathrm{ml}$ according to the method of Van der Ploeg et al. (1984, 1989). The digestion of the blocks was carried out in $0.5 \mathrm{M}$ EDTA (ethylenedinitrilotetraacetic acid, Titriplex III) pH 9.0, $1 \%$ sodium $\mathrm{N}$-lauryl sarcosinate supplemented with proteinase $K(0.5 \mathrm{mg} / \mathrm{ml})$ for $48 \mathrm{~h}$ at $50^{\circ} \mathrm{C}$. After rinsing the blocks 3 times in $50 \mathrm{~mm}$ EDTA, pH 8.0 , the samples were stored in the same solution at $4{ }^{\circ} \mathrm{C}$.

For electrophoresis, chromosome blocks were inserted into the sample slots of a $15 \times 15 \mathrm{~cm} 1 \%$ agarose gel in $89 \mathrm{~mm}$ Tris (tris[hydroxymethyl]aminomethane), $89 \mathrm{~mm}$ boric acid, $0.2 \mathrm{~mm}$ EDTA. The gel was run in an LKB Pulsaphor system with 
a hexagonal electrode array. The electrode buffer was the same as in the gel and was maintained at $14^{\circ} \mathrm{C}$. Pulses of different frequencies were applied in $\mathrm{N}-\mathrm{S}$ and $\mathrm{E}-\mathrm{W}$ directions. In order to resolve different size ranges of chromosomes, three different sets of running conditions (I, II and III) involving different pulse frequencies and durations of electrophoresis were applied. Whereas program I (4 phases: $300 \mathrm{~s}(12 \mathrm{~h}), 200 \mathrm{~s}(18 \mathrm{~h}), 150 \mathrm{~s}(24 \mathrm{~h}), 100 \mathrm{~s}(18 \mathrm{~h})$; $110 \mathrm{~V}$ ) provides a good resolution of the intermediate (100-720 kilobases) size chromosomes, program II ( 5 phases: $900 \mathrm{~s}(24 \mathrm{~h}), 750 \mathrm{~s}(24 \mathrm{~h}), 700 \mathrm{~s}(24 \mathrm{~h})$, $600 \mathrm{~s}(24 \mathrm{~h}), 500 \mathrm{~s}(24 \mathrm{~h}) ; 82 \cdot 5 \mathrm{~V})$ and program III (6 phases: $1200 \mathrm{~s}(24 \mathrm{~h}), 1000 \mathrm{~s}(24 \mathrm{~h}), 900 \mathrm{~s}(24 \mathrm{~h})$, $800 \mathrm{~s}(24 \mathrm{~h}), 700 \mathrm{~s}(24 \mathrm{~h}), 600 \mathrm{~s}(24 \mathrm{~h}) ; 82.5 \mathrm{~V})$ allow the separation of larger chromosomes ranging from 1 to $3 \mathrm{Mb}$. After separation, the gel was stained in an ethidium bromide solution ( $46 \mathrm{~mm}$ Tris, $46 \mathrm{~mm}$ boric acid, $0.1 \mathrm{~mm}$ EDTA, $2 \mu \mathrm{g} / \mathrm{ml}$ ethidium bromide) for $2-8 \mathrm{~h}$ and subsequently destained in the same buffer without ethidium bromide.

PFGE gel separations were blotted as described by Hide et al. (1990) with the exception that the DNA was transferred to nylon filters (Hybond-N, Amersham) and cross-linked to the filter by exposure to long-wave ultra-violet light for $7 \mathrm{~min}$. The filter was pre-hybridized for $30 \mathrm{~min}$ in $0.5 \mathrm{M}$ phosphate buffer ( $\mathrm{pH} 7 \cdot 2$ ), $7 \%$ SDS (dodecylsulfate sodium salt) at $65^{\circ} \mathrm{C}$ and subsequently hybridized with $10^{7} \mathrm{cpm}$ (counts $/ \mathrm{min}$ ) of the appropriate labelled DNA probe overnight at the same temperature in the same buffer. Subsequently the filter was washed twice for $15 \mathrm{~min}$ in $0.1 \% \mathrm{SDS}, 2 \times \mathrm{SSC}$ (salinesodium citrate buffer) at $65^{\circ} \mathrm{C}$ before being exposed to the $\mathrm{X}$-ray film at $-70^{\circ} \mathrm{C}$. Filters were hybridized with DNA fragments coding for the phosphoglycerate kinase (PGK) gene (Osinga et al. 1985) and for the cysteine protease (CP) gene (Mottram et al. 1989). The probes were labelled using a random primer labelling kit (Boehringer) as directed by the manufacturer.

\section{RESULTS}

\section{Frequency of hybrid formation}

In order to obtain information on the frequency of hybrid formation with the new combination of parental clones, 7 infective tsetse flies were randomly chosen to feed on individual mice at different times after Glossina infection. The results of the characterization of 17 of the subsequent bloodstream-form populations by isoenzyme analysis for ICD are summarized in Table 1 ; hybrids are identified by the presence of a heterozygous ICD pattern as described previously (Jenni et al. 1986). The results indicate that of the 7 Glossina examined, at least 2 extruded trypsanosome populations containing hybrid organisms on at least one occasion. This observation is in
Table 2. Phenotypes (isoenzymes) and genotypes (RFLPs) of parental and progeny clones

(Isoenzymes: the electrophoretic variants are denoted by numbers; a single number defining a single band of activity and a pair of hyphenated numbers indicating multiple bands of activity typical of a heterozygous pattern. ICD: isocitrate dehydrogenase; AP: alkaline phosphatase; $\mathrm{ME}_{\mathbf{B}}$ : malic enzyme B. RFLPs: markers were used for which one of the parentals is heterozygous. Clones were screened with a cDNA-clone of phosphoglycerate kinase (PGK) or a polymerase I probe (Pol I) using DNA digested with the enzymes indicated.)

\begin{tabular}{|c|c|c|c|c|c|}
\hline \multirow[b]{3}{*}{ Clone } & \multirow{2}{*}{\multicolumn{3}{|c|}{ Isoenzymes }} & \multicolumn{2}{|c|}{ RFLPs } \\
\hline & & & & \multirow{2}{*}{$\begin{array}{l}\text { PGK } \\
\text { PstI }\end{array}$} & \multirow{2}{*}{$\begin{array}{l}\text { Poll } \\
\text { Hind III }\end{array}$} \\
\hline & ICD & $\mathrm{AP}$ & $\mathrm{ME}_{\mathrm{B}}$ & & \\
\hline \multicolumn{6}{|l|}{ Parental: } \\
\hline$S T I B 247-L F$ & 1 & 1 & 3 & ++ & -- \\
\hline$S T I B \quad 777-A$ & 2 & $1-2$ & $2-3$ & +- & +- \\
\hline \multicolumn{6}{|l|}{ Progeny: } \\
\hline$S T I B$ 787-IA & $1-2$ & 1 & $2-3$ & +- & -- \\
\hline$S T I B$ 787-IB & $1-2$ & 1 & $2-3$ & $+t$ & +- \\
\hline$S T I B$ 787-IC & $1-2$ & 1 & $2-3$ & $+t$ & +- \\
\hline$S T I B \quad 787-I D$ & $1-2$ & $1-2$ & $2-3$ & ++ & -- \\
\hline
\end{tabular}

accordance with earlier findings in mixed infection experiments in relation to the frequency of hybrids produced (Schweizer et al. 1988; Sternberg et al. 1989; Turner et al. 1990).

\section{Enzyme phenotype of progeny clones}

Parental and progeny clones were characterized by starch gel electrophoresis (ICD and AP) or isoelectric focusing $\left(\mathrm{ME}_{\mathrm{B}}\right)$ of extracts for 3 marker enzymes. The results obtained are shown in Table 2. The 4 progeny clones can be classified into 2 phenotypic classes (class 1 and class 2) which are non-parental and distinguishable solely by APpattern. Whereas all 4 progeny clones show a nonparental 3-banded hybrid ICD-pattern and a P2-type $\mathrm{ME}_{\mathrm{B}}$-banding, 3 of them (class 1) express a P1-type AP-phenotype ( $S T I B$ 787-IA, 787-IB and 787-IC) and 1 (STIB 787-ID) shows a P2-type AP-pattern (class 2).

The enzyme phenotypes observed at each of these loci are compatible with a simple Mendelian pattern of inheritance. They represent 2 of 4 possible phenotypic F1 progeny classes that would be predicted if meiosis had occurred either before or after the genetic exchange event which led to hybrid formation.

\section{Restriction fragment length polymorphism analysis}

Bloodstream forms of all 4 progeny clones were analysed together with the parental stocks by Southern blotting of restriction digests of nuclear 

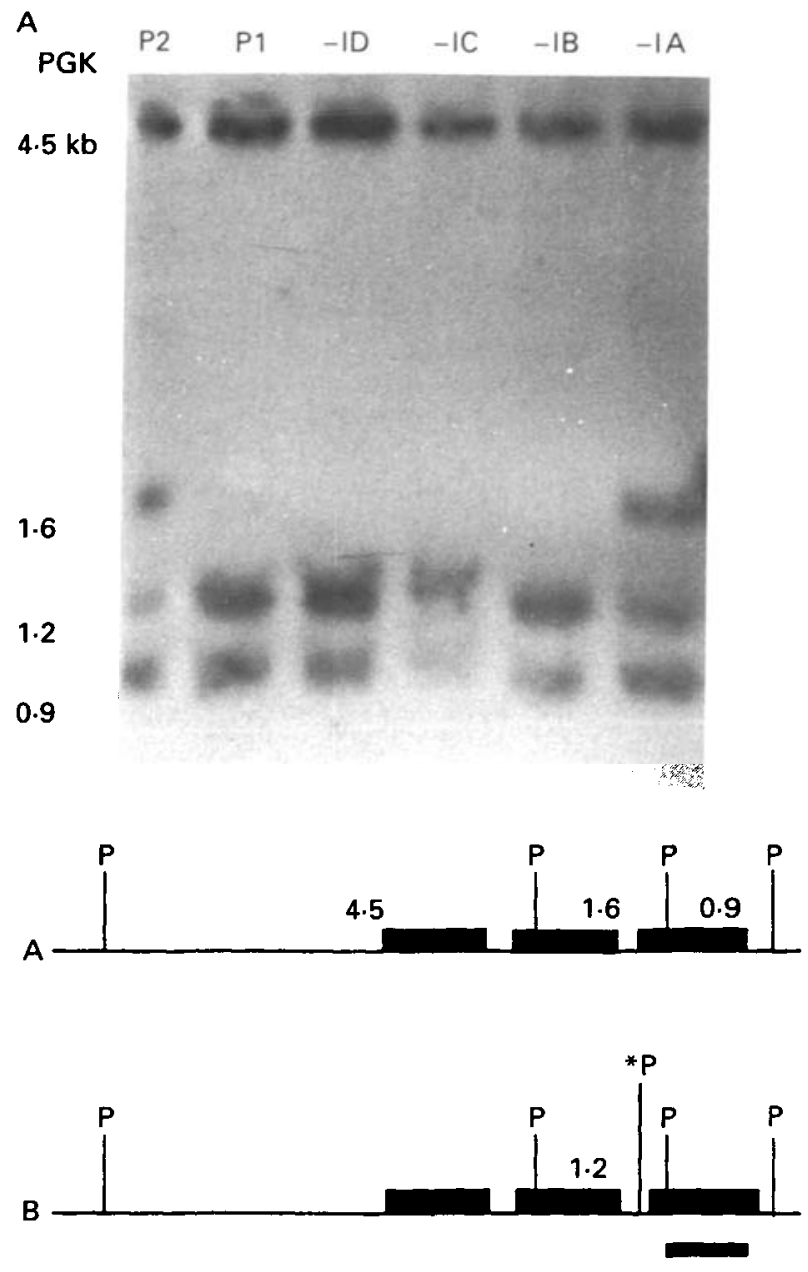
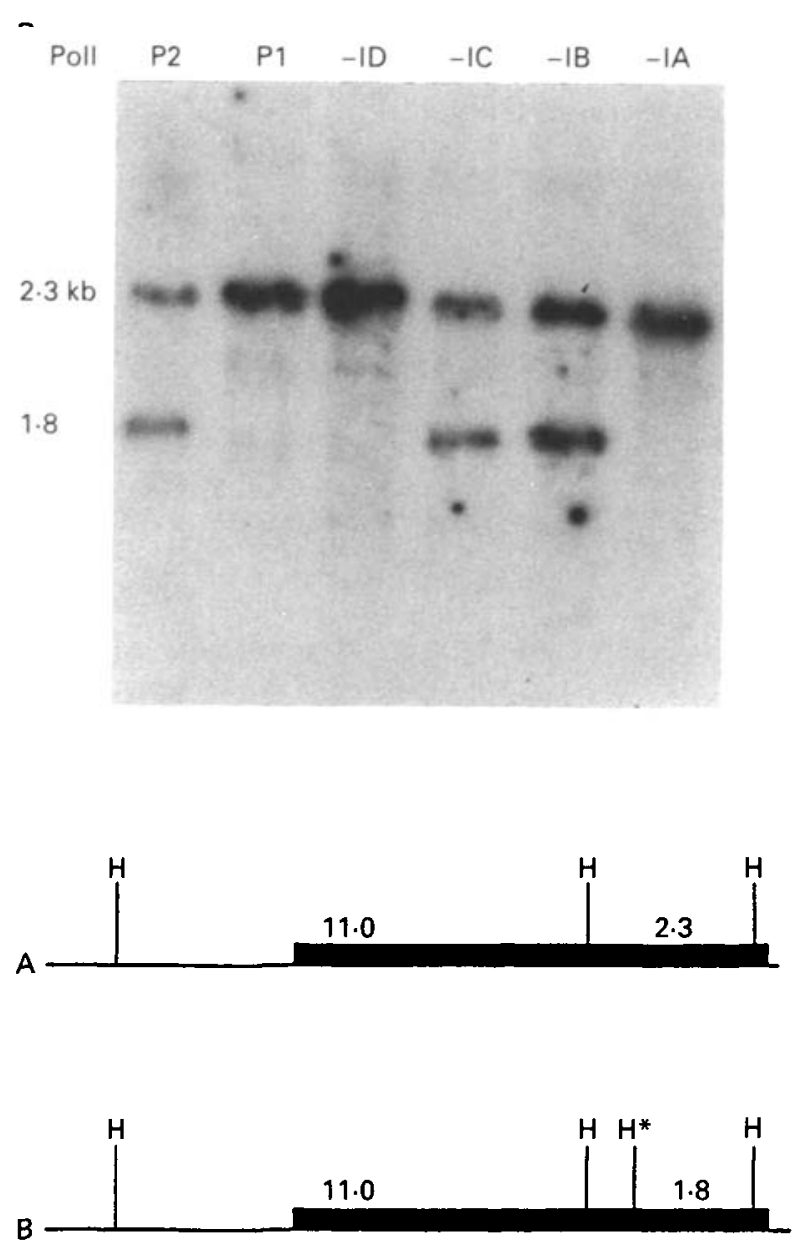

Fig. 1. (A) Autoradiograph of a Southern blot of total genomic DNA digested with Pst 1 and probed with a cDNA clone of phosphoglycerate kinase (PGK). The DNA was extracted from two parental stocks $P 1, P 2:$ parental clones $S T I B \quad 247-L F$ and $S T I B 777-A$ and four progeny clones $-I A,-I B,-I C,-I D: S T I B 787-I A, 787-I B, 787-I C$ and $787-1 D$. Below the panel is a map to show the alleles involved, with the 3 homologous PGK genes shown as black boxes and an asterisk marking the polymorphic site; the position of the probe is indicated by a bar beneath the map. (B) Autoradiograph of Southern blot of total genomic DNA digested with HindIII and probed with a DNA probe of polymerase I(PolI), Parental stock: $P 2: S T I B$ 777- $A$; $P 1: S T I B$ 247-LF; progeny: $-I A,-I B,-I C, I D: S T I B$ 787$I A, 787-I B, 787-I C$ and $787-I D$.

DNA using a probe for the phosphoglycerate kinase gene (PGK-960 bp Pst 1 fragment from phosphoglycerate kinase cDNA clone pTcPGK8 (Osinga $e t$ al. 1985)) and a probe for RNA-polymerase I (Pol I; Jess et al. 1989). The restriction pattern of $S T I B$ 247-LF (P1) can be interpreted as being homozygous for the presence of a Pst 1 restriction site detected by PGK and is identical with the pattern of STIB 386 (Turner et al. 1990) whereas $S T I B$ 777- $A(\mathrm{P} 2)$ is heterozygous for the presence/ absence of this site. Of the 4 progeny clones, $S T I B$ 787- $I A$ clearly shows the heterozygous pattern of P2, while $S T I B 787-I B, S T I B 787-I C$ and $S T I B$ 787-ID show the homozygous pattern of $\mathrm{P} 1$ (Fig. 1A).

A further polymorphism is detected by the DNA probe Pol I : $S T I B$ 777- $A(\mathrm{P} 2)$ shows a heterozygous pattern whereas $S T I B 247-L F(\mathrm{P} 1)$ has a homozygous 1-banded pattern (Fig. 1B); the progeny clones $S T I B$ 787-IA and STIB 787-ID show the same homozygous band as $S T I B$ 247- $L F$ while the progeny clones $S T I B$ 787-IB and $S T I B$ 787-IC show a heterozygous pattern.

This finding underpins the postulate that the progeny are products of syngamy. Considering the segregation of the alleles at the loci for ICD, AP, $\mathrm{ME}_{\mathrm{B}}$ (isoenzymes) and PGK, Pol I (RFLPs) in the cross, it can be seen that 3 classes of $F 1$ progeny are generated (Table 2). The non-parental combinations of alleles of these 3 classes show that the alleles at each locus segregate. $S T I B 787-I B$ and $S T I B 787-$ $I C$ were identical according to all markers for which they were analysed.

\section{Molecular karyotype analysis}

The analysis of intermediate size chromosomes (Fig. $2 A)$ reveals that the parental clone $S T I B$ 247-LF (P1) shows a single band at $440 \mathrm{~kb}$ while clone $S T I B 777-A(\mathrm{P} 2)$ shows 7 bands ranging in size 
A

P1 P2 -ID -IC - IB - IA P1

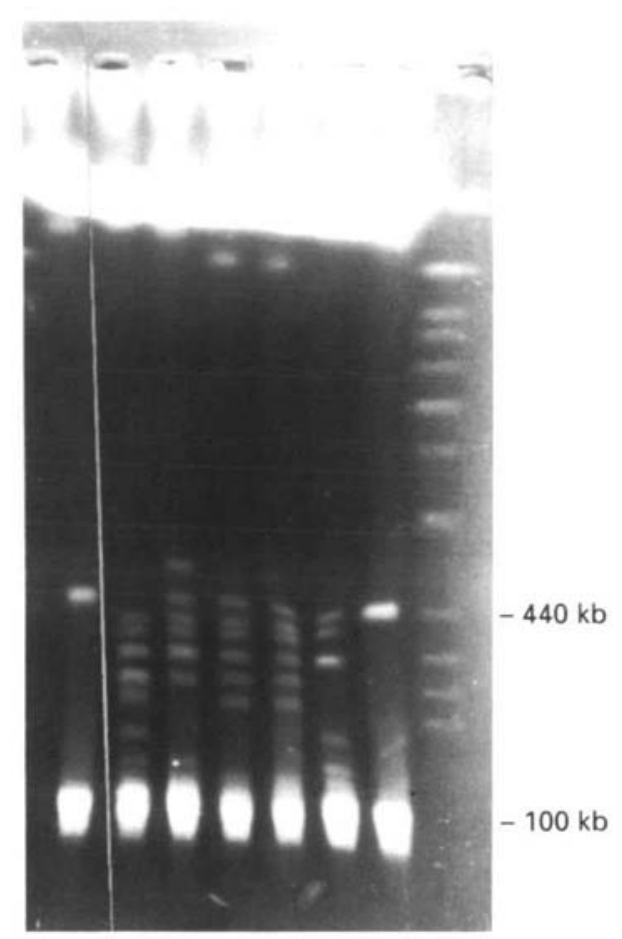

B

\begin{tabular}{|c|c|c|c|c|c|c|c|c|c|}
\hline \multirow[b]{2}{*}{ Clone } & \multicolumn{9}{|c|}{ Chromosome size $(\mathrm{kb})$} \\
\hline & 100 & 200 & 280 & 300 & 340 & 370 & 400 & 440 & 490 \\
\hline \multicolumn{10}{|l|}{ Parental } \\
\hline 247-LF (P1) & & & & & & & & + & \\
\hline 777-A (P2) & + & + & + & + & + & + & + & & \\
\hline \multicolumn{10}{|l|}{ Progeny: } \\
\hline 787-IA & + & + & & & + & & + & + & \\
\hline 787-IB & & & + & + & + & + & + & + & \\
\hline 787-IC & & & + & + & + & + & + & + & \\
\hline 787-ID & + & & & + & + & + & + & + & + \\
\hline
\end{tabular}

Fig. 2. (A) Ethidium bromide-stained PFGE run using program $I$ to give increased resolution in the size range 100-720 kb. Stocks are: P1, P2: parental clones $S T I B$ 247-LF and $S T I B$ 777- $A$ respectively; -IA, -IB, -IC, -ID: progeny clones $S T I B$ 787-IA, 787-IB, 787-IC and 787-ID respectively. (B) Table to (A) summarizing the data on chromosomes observed ranging in the size 100 and $490 \mathrm{~kb}$.

from 100 to $400 \mathrm{~kb}$. None of the 4 progeny clones shows a pattern identical to either parental clone or to the sum of both parental types; by this criterion the progeny are all recombinant. The intermediate size chromosomes are thought to contain primarily repetitive sequences and VSG genes; on the assumption that identical size indicates an identical chromosome, all progeny clones inherit the P1 parental chromosomes of $440 \mathrm{~kb}$ and the $\mathrm{P} 2$ parental chromosomes of $340 \mathrm{~kb}$ and $400 \mathrm{~kb}$ together with a varying number - but never all - of the remaining $\mathrm{P} 2$ chromosomes. The progeny can be grouped into 3 classes. One class consists of $S T I B$ 787-IA with 5 chromosomes. A second includes both $S T I B$ 787-IB and $S T I B$ 787-IC which show an identical pattern with 6 bands. The third class consists of progeny clone $S T I B$ 787-ID which has 7 bands, one representing a non-parental chromosome of novel size, approximately equal to the sum of the sizes of the two chromosomes not present (200 and $280 \mathrm{~kb}$ ). These results are summarized in Fig. $2 B$.

The large chromosomes were separated using two different running conditions which resolve chromosomes in different size ranges. The ethidium bromide stained pattern of the parental stocks and resulting hybrid clones separated under program II are illustrated in Fig. 3A. It is clear that the hybrid progeny are different from either parental clone and that hybrids $-I B$ and $-I C$ are identical. Most of the chromosome bands in the hybrid clones can, on the basis of size, be accounted for as having originated from one or other parent; however, one band in 
A

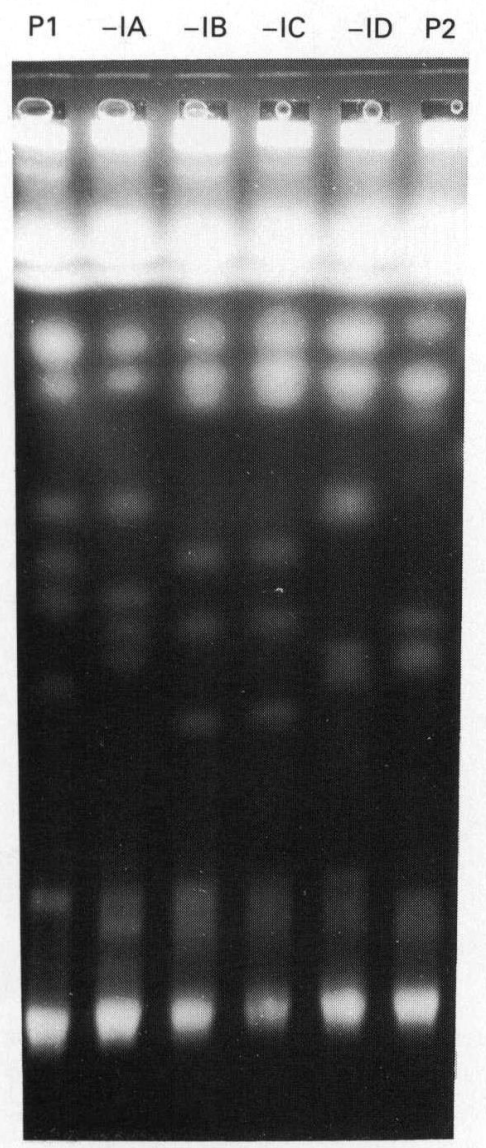

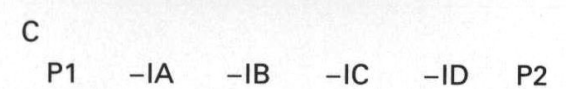

B
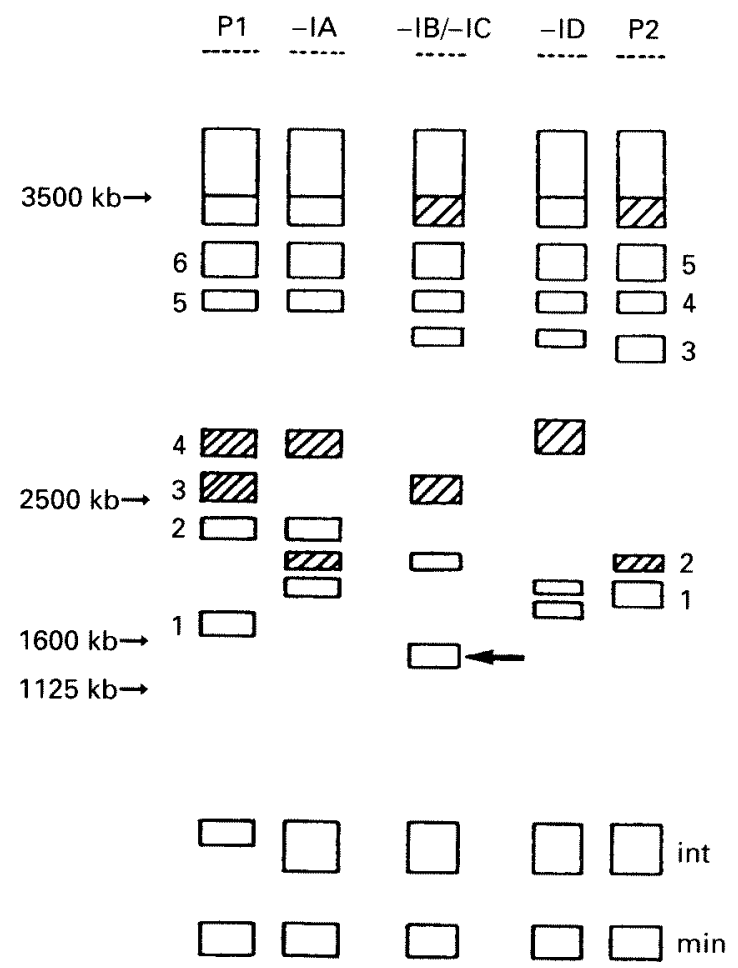

-PGK

Fig. 3. PFGE analysis of PGK and CP gene inheritance. (A) Ethidium bromide-stained PFGE run using program II for separation of larger chromosomes $(1-3 \mathrm{Mb})$; the designation of the tracks is as in Fig. 1. (B) Diagram of the bands in (A). For better identification the chromosomes of the parental clones within the range of interest are numbered. $-\mathrm{IB} /-\mathrm{IC}$ shows the patterns of progeny, 787-IB and $787-I C$ respectively, and min and int indicate the position of the 'mini' and the intermediate sized chromosomes. Arrows point to non-parental size chromosomes (novel size bands). Bands which hybridize with a probe for PGK are hatched. (C) Blot of the gel in (A) hybridized with the PGK-probe. 
clones $-I B$ and $-I C$ is of novel size (arrows in Fig. 3B) not found in either parent. In order to identify homologous chromosomes, a blot of the gel was probed with a cDNA clone of PGK and the hybridization pattern obtained is illustrated schematically in Fig. 3B and C. Hybridization to bands 3 and 4 in $\mathrm{P} 1$ and band 2 and the compression zone in $\mathrm{P} 2$ is observed. Hybrid $-I A$ inherits band $2(\mathrm{P} 2)$ and band 4 (P1) while hybrids $-I B /-I C$ inherit the compression zone chromosome (P2) and band $3(\mathrm{P} 1)$ as would be predicted if these chromosomes were homologues in the parental clones and the hybrid progeny inherited one homologue from each parent. Hybrid $-I D$ shows only a single band of hybridization of greater intensity than the other hybrids and of a similar mobility to band 4 (P1). Further data are presented and discussed below in relation to this pattern of hybridization.

Greater resolution of the larger chromosomes was obtained using program III and the ethidiumstained gel using these conditions is shown in Fig. 4A. By comparison to the parental karyotype, it is clear that the hybrids are recombinant and in hybrids $-I D$ and $-I B /-I C$ novel, non-parental size chromosomes are observed (arrowed, Fig. 4B). In order to confirm the results obtained with the PGK cDNA probe, the gel was blotted and hybridized with this probe. The results are presented in Fig. $4 \mathrm{C}$ and diagrammatically in Fig. $4 \mathrm{~B}$ and are essentially similar to those in Fig. 3. Progeny clone STIB 787$I D$ shows an odd pattern with a single broad hybridization band of the same size as band 4 of $\mathrm{P} 1$. A possible explanation could be that the single band consists of band 4 from $\mathrm{P} 1$ and a novel size chromosome from $\mathrm{P} 2$; however, further data are required to establish this.

In order to establish whether other pairs of homologous chromosomes behave in the same way, the blot of the gel shown in Fig. 4 was probed with a cysteine proteinase gene probe (CP; Fig. 4D). The $\mathrm{CP}$ probe shows a single banding pattern for parental clone P1 (band 6) and a double banding pattern (bands 5 and 6) for P2. From the intensity of the single band (see also Fig. $4 \mathrm{~A}$ and $\mathrm{B}$ ) one could assume that it contains 2 homologues of identical or nearly identical size. The progeny clones $787-I A$ and $-I D$ appear identical to $\mathrm{P} 2$, but could equally be due to the inheritance of 1 homologue from $\mathrm{P} 1$ and band 6 from $P 2$. STIB 787-IB and $-I C$ respectively show a non-parental double banding pattern; one band is of the same size as band 6 (P1) or band 5 (P2) and the second represents a novel size band which could be derived from either parent.

These results indicate that there is evidence for normal Mendelian inheritance, i.e. of 1 homologue from each parent, but in addition we find chromosomes of a novel size in some clones. This finding could be explained by recombination between different-sized homologues at meiosis, and the generation of novel size chromosomes.

\section{DISCUSSION}

This publication reports an analysis of the products of a new genetic cross of two East African T. brucei clones. The inheritance of isoenzyme and RFLP markers from the parents to the progeny was examined. Clones were heterozygous for markers for which parents were homozygous and segregation of alleles was observed for phenotypic and genotypic markers. The four hybrid clones provided evidence that karyogamy and/or meiosis had occurred; this is in accordance with observations from other mixed infection experiments (Gibson \& Garside, 1990; Tait \& Turner, 1990; Turner et al. 1990).

Clones derived from hybrid-containing populations showed heterozygous hybrid pattern for the isoenzyme ICD. The four hybrid clones were further analysed by both isoenzyme ( $\mathrm{AP}$ and $\mathrm{ME}_{\mathrm{B}}$ ) and gene (PGK and pol I) markers for which the 777- $A$ parent is heterozygous but the $247-L F$ parent is homozygous. Two of the clones (787-IB and 787IC) were identical but recombinant while the remaining two cones $(787-I A$ and $787-I D)$ were distinct from each other and the first two clones but were also recombinant. Thus allelic segregation occurred at each locus and recombination between alleles at each locus. These results are those predicted of a normal diploid Mendelian system involving meiosis. The analysis of RFLPs showed three different non-parental combinations of alleles and showed that alleles segregate at each locus as reported for a different cross by Turner et al. 1990.

The inheritance of the intermediate chromosomes was examined and as has been reported with other crosses (Jenni et al. 1986; Wells et al. 1987; Gibson, 1989) these did not appear to be inherited in a Mendelian manner. The single $(440 \mathrm{~kb})$ intermediate chromosome of stock STIB 247-LF was inherited by all progeny clones but a variable number of the chromosomes from stock $S T I B$ 777- $A$ leading to a range of intermediate karyotypes in the progeny clones. These results support the view that the intermediate chromosomes do not behave as pairs of homologues and so segregate at random into the progeny clones and are therefore inherited in a nonMendelian manner. The additional detection of a non-parental size chromosome in one of the progeny clones is in accordance with results from Gibson (1989), who interpreted the novel chromosome as a product of the gene rearrangements associated with antigenic variation, or of a recombination associated with genetic exchange.

The analysis of the inheritance of large chromosomes in four hybrid progeny clones revealed that 
A

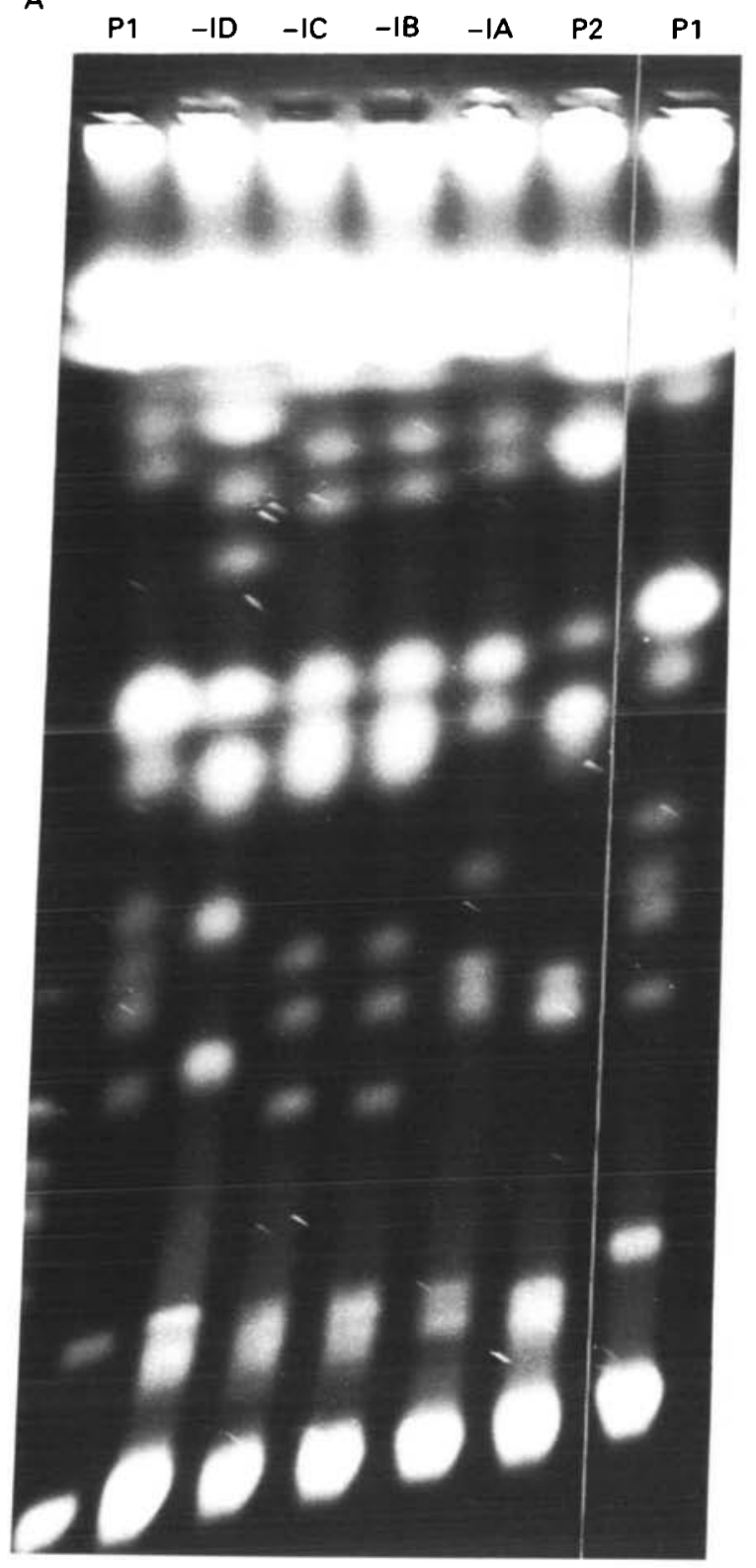

B

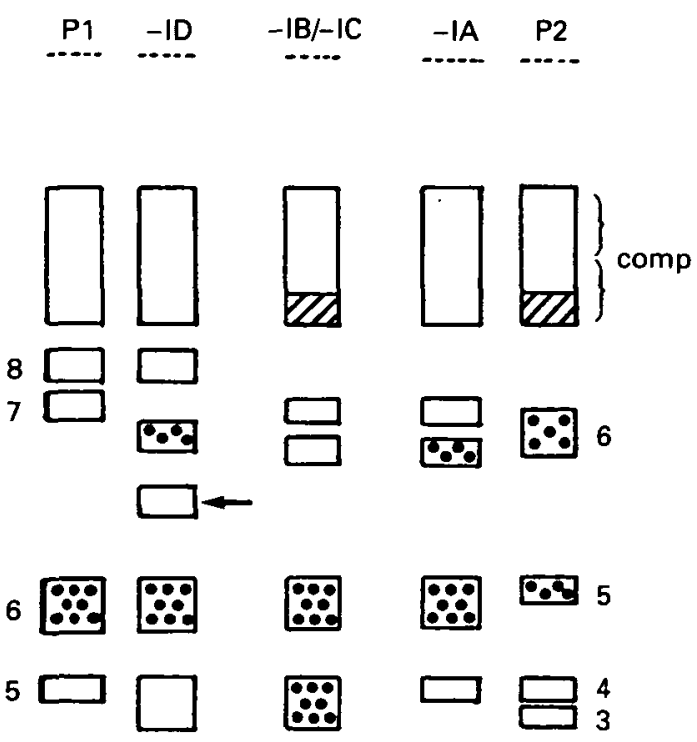

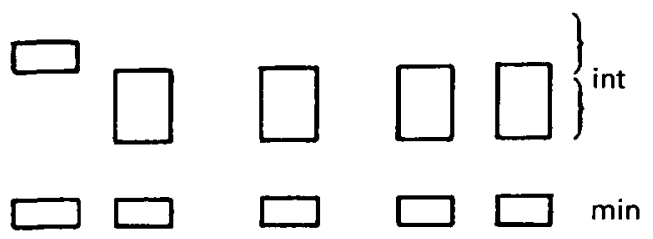

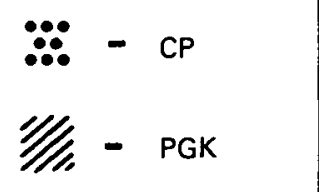

Fig. 4. For legend see opposite.

three clones possessed novel-sized (non-parental) chromosomes. This finding could be explained by recombination between homologues differing in size at meiosis, although other explanations are possible. Evidence for such discrepancies in size between homologues can be shown by Southern analysis of chromosomes, a technique which represents a powerful method for determining the fate of chromosomes. Thus the evidence presented shows that putative homologues harbouring the PGK genes were of different sizes in the two parentals; the $\mathrm{F} 1$ progeny clones $-I A,-I B$ and $-I C$ inherit one chromosome (hybridizing to PGK) from each parent (Fig. 4C) which is consistent with the two bands identified in each of the parental stocks behaving as homologues and segregating at meiosis. Progeny clone $-I D$, however, shows a single broad band of hybridization; without additional markers for each putative parental homologue this result is difficult to interpret. Analysis of the chromosomes detected by the cysteine proteinase gene probe for progeny clones $-I A$ and $-I D$ is also consistent with these hybrids inheriting one homologue from each parent; however, progeny clones $-I B$ and $-I C$ show a novel nonparental karyotype which, without further data, is difficult to interpret conclusively. Results which 

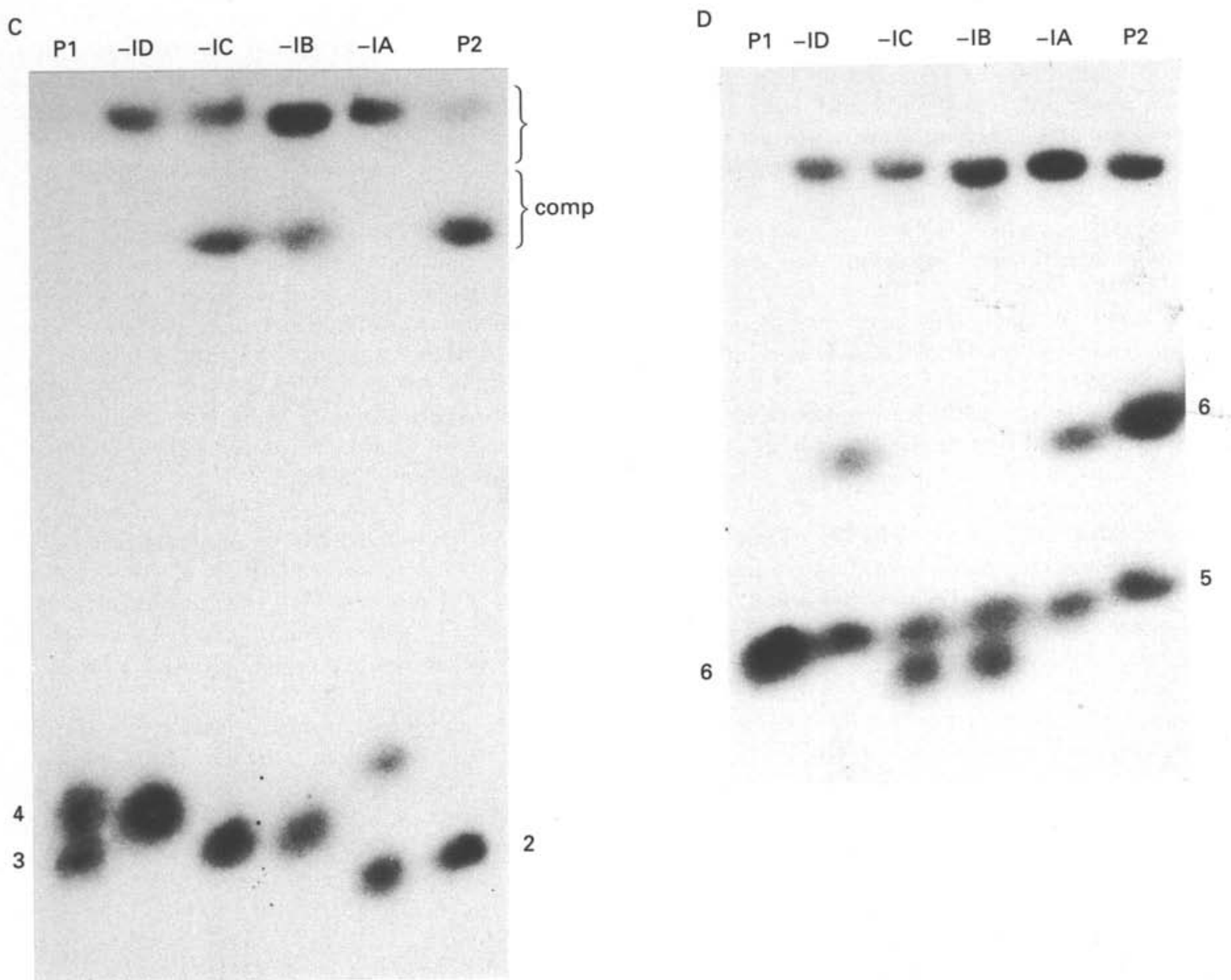

Fig. 4. PFGE analysis of PGK and CP gene inheritance. (A) Ethidium bromide-stained PFGE gel using program III for the separation of the chromosomes in the range from 1 to $3 \mathrm{Mb}$. The lanes are designated as in Fig. 2 . (B) Diagram of the bands in (A) including results from the PGK and CP blot. Numbering of the bands is as in Fig. 2; min, int and comp indicate the area of the mini-chromosomes, the intermediate size chromosomes and the compression zone respectively. The arrow indicates a non-parental band of novel size. (C) Blot of the gel in (A) hybridized with the PGK-probe. (D) Blot of the gel in (A) hybridized with the CP-probe. The hybridization observed at the slot region can be ignored on the assumption that it is due to trapping.

indicate that homologous chromosomes can differ in size have been provided by other authors (Gibson et al. 1985; Gibson, 1989; Gottesdiener et al. 1990) but the mechanisms by which these size differences arise remain to be elucidated. One interpretation of the data presented here is that such size differences are generated during or after genetic exchange but further markers for each homologue of a chromosome pair are required in order to establish this.

The results imply that the progeny clones are not the products of a simple fusion but fit into a classical system with meiosis and subsequent fusion of the nuclei to form diploid progeny. Previous reports (Paindavoine et al. 1986; Wells et al. 1987; Gibson, Garside \& Bailey, 1992) have identified hybrid progeny with raised DNA contents. Two of these clones (Gibson et al. 1992) have been characterized in terms of their molecular karyotype and shown to be trisomic at least for some of the chromosomes.
Our data, based on molecular karyotype analysis, suggest that the hybrids produced in the cross between $S T I B 247-L F$ and $S T I B 777-A$ are diploid and provide further evidence that the production of hybrids with raised DNA content is a relatively rare event (Tait \& Turner, 1990). However, it may be that such hybrids are generated at relatively high frequency but are selected against during the growth of trypanosomes from hybrid producing tsetse flies.

We are grateful to Dr D. Moloo from ILRAD, Nairobi, Kenya, for the supply of tsetse pupae and to Mrs J. M. Jenkins for critical reading of the manuscript. This study was supported by the Swiss National Science Foundation grant No. 31-25367.88 I/II (J.S., H.P., L. J) and by a grant from the Wellcome Trust (G.H., N. B., A. T.) This work forms part of the material for the Ph.D. theses of $\mathrm{H}$. Pospichal and J. Schweizer at the University of Basel. 


\section{REFERENCES}

BRUN, R. \& SCHÖNENBERGER, M. (1981). Stimulating effect of citrate and cis-aconitate on the transformation of Trypanosoma brucei bloodstream forms to procyclic forms in vitro. Zeitschrift für Parasitenkunde 66, $17-24$.

GEIGY, R. \& KAUFFMANN, M. (1973). Sleeping sickness survey in the Serengeti Area (Tanzania) 1971. Acta Tropica 30, 12-48.

GIBson, w. C. (1989). Analysis of a genetic cross between Trypanosoma brucei rhodesiense and T. b. brucei. Parasitology 99, 391-402.

GIBSON, W. C. \& GARSIDE, L. (1990). Kinetoplast DNA minicircles are inherited from both parents in genetic hybrids of Trypanosoma brucei. Molecular and Biochemical Parasitology 42, 45-54.

gibson, w. C., Garside, L. \& BaIley, M. (1992). Trisomy and chromosome size changes in hybrid trypanosomes from a genetic cross between Trypanosoma brucei rhodesiense and T. b. brucei. Molecular and Biochemical Parasitology 52, 189-200.

GIBSON, W. C. GASHUMBA, J. K. (1983). Isoenzyme characterization of some Trypanozoon stocks from a recent trypanosomiasis epidemic in Uganda. Transactions of the Royal Society of Tropical Medicine and Hygiene 77, 114-18.

GIBSON, W. C., MARShall, T. F. DE C. \& GODFREY, D. G. (1980). Numerical analysis of enzyme polymorphism: a new approach to the epidemiology and taxonomy of trypanosomes of the subgenus Trypanozoon. Advances in Parasitology 18, 175-246.

GIBSON, W. C., OSINGA, K. A., MICHELS, P. A. M. \& BORST, P. (1985). Trypanosomes of subgenus Trypanozoon are diploid for housekeeping genes. Molecular and Biochemical Parasitology 16, 231-42.

GiBson, w. \& WHITTINGTON, H. (1993). Genetic exchange in Trypanosoma brucei: selection of hybrid trypanosomes by introduction of genes conferring drug resistance. Molecular and Biochemical Parasitology 60, 19-26.

GOTTESDIENER, K., GARCIÁ-ÃNOVEROS, J., LEE, M. G.-S. \& VAN DER PLOEG, L. H. T. (1990). Chromosome organization of the protozoan Trypanosoma brucei. Molecular and Cellular Biology 10, 6079-83.

HIDE, G., CATTAND, P., LERAY, D., BARRY, J. D. \& TAIT, A. (1990). The identification of Trypanosoma brucei subspecies using repetitive DNA sequences. Molecular and Biochemical Parasitology 39, 213-26.

JENNI, L., MARTI, S., SCHWEIZER, J., BETSCHART, B., LE PAGE, R. W. F., WELls, J. M., TAIT, A., PAINDAVOINe, P., PAYS, E. \& STEINERT, M. (1986). Hybrid formation between African trypanosomes during cyclical transmission. Nature, London 322, 173-5.

JEss, W., hammer, A. \& CORNELISSEN, A. W. C. A. (1989). Complete sequence of the gene encoding the largest subunit of RNA polymerase I of Trypanosoma brucei. FEBS Letters 249, 123-8.

MOTTRAM, J. C., NORTH, M. J., BARRY, J. D. \& COOMBS, G. H. (1989). A cysteine proteinase cDNA from Trypanosoma brucei predicts an enzyme with an unusual C-terminal extension. FEBS Letters 258, 211-15.
OSINGA, K. A., SWINkELS, B. W., GIBSON, W. C., BORST, P., VEENEMAN, G. H., VAN BOOM, J. H., MICHELS, P. A. M. \& OPPERDOES, F. R. (1985). Topogenesis of microbody enzymes: a sequence comparison of the genes for the glycosomal (microbody) and cytosolic phosphoglycerate kinases of Trypanosoma brucei. EMBO Fournal 4, 3811-17.

PAINDAVOINE, P., ZAMPETTI-BOSSELER, F., PAYS, E., SCHWEIZER, J., GUYAUX, M., JENNI, L. \& STEINERT, M. (1986). Trypanosome hybrids generated in tsetse flies by nuclear fusion. EMBO fournal 5, 3631-6.

RICHNER, D., SCHWEIZER, J., BETSCHART, B. \& JENNI, L. (1989). Characterization of West African Trypanosoma (Trypanozoon) brucei isolates from man and animals using isoenzyme analysis and DNA hybridization. Parasitology Research 76, 80-5.

SCHWARTz, D. C. \& CANTOR, C. R. (1984) Separation of yeast chromosome-sized DNAs by pulsed field gradient gel electrophoresis. Cell 37, 67-75.

SCHWEIZER, J. \& JENNI, L. (1991). Hybrid formation in the life-cycle of Trypanosoma (T.) brucei: detection of hybrid trypanosomes in a midgut-derived isolate. Acta Tropica 48, 319-21.

SCHWEIZER, J., POSPICHAL, H. \& JENNI, L. (1991). Hybrid formation between African trypanosomes in vitro. Acta Tropica 49, 237-40.

SCHWEIZER, J., TAIT, A. \& JENNI, L. (1988). The timing and frequency of hybrid formation in African trypanosomes during cyclical transmission.

Parasitology Research 75, 98-101.

STERNBERG, J., TAIT, A., HALEY, S., WElls, J. M., LE PAGE, R. W. F., SCHWEIZER, J. \& JENNI, L. (1988). Gene exchange in African trypanosomes: characterisation of a new hybrid genotype. Molecular and Biochemical Parasitology 27, 191-200.

STERNBERG, J., TURNER, C. M. R., WELLS, J. M., RANFORDCARTWRIGHT, L. C., LE PAGE, R. W. F. \& TAIT, A. (1989). Gene exchange in African trypanosomes: frequency and allelic segregation. Molecular and Biochemical Parasitology 34, 269-80.

TAIT, A. (1980). Evidence for diploidy and mating in trypanosomes. Nature, London 287, 536-8.

TAIT, A., BABIKER, E. A. \& LE RAY, D. (1984): Enzyme variation in Trypanosoma brucei spp. 1. Evidence for sub-speciation of Trypanosoma brucei gambiense. Parasitology 89, 311-26.

TAIT, A., BARRY, J. D., WINK, R., SANDERSON, A. \& CROWE, J. S. (1985). Enzyme variation in T. brucei spp. II. Evidence for $T$. $b$. rhodesiense being a set of variants of T. b. brucei. Parasitology 90, 89-100.

TAIT, A. \& TURNER, C. M. R. (1990). Genetic exchange in Trypanosoma brucei. Parasitology Today 6, 70-5.

TURNER, C. M. R., STERNBERG, J., BUCHANAN, N., SMITH, E., HIDE, G. \& TAIT, A. (1990). Evidence that the mechanism of gene exchange in Trypanosoma brucei involves meiosis and syngamy. Parasitology 101, $377-86$.

VAN DER PLOEG, L. H. T., SCHWARTZ, D. C., CANTOR, C. R. \& BORST, P. (1984). Antigenic variation in Trypanosoma bruce $i$ analyzed by electrophoretic separation of chromosome-sized DNA molecules. Cell 37, 77-84.

VAN DER PlOEG, L. H. T., SMITH, C. L., POLVERE, R. I. \& GOTTESDIENER, K. M. (1989). Improved separation of 
chromosome-sized DNA from Trypanosoma brucei stock, 427-60. Nucleic Acids Research 17, 3217-27.

VAN MeirvenNe, N., Janssens, P. G. \& Magnus, E. (1975).

Antigenic variation in syringe passaged populations of Trypanosoma (Trypanozoon) brucei : rationalization of the experimental approach. Annales de la Société belge de Médecine tropicale 55, 1-23.
WELls, J. M., PROSPERO, T. D., JENNI, L. \& LE PAGE, R. W. F. (1987). DNA contents and molecular karyotypes of hybrid Trypanosoma brucei. Molecular and Biochemical Parasitology 249, 103-16. 